\title{
Land degradation sensitivity assessment and convergence analysis in Korla of Xinjiang, China
}

\author{
DING Jinchen, CHEN Yunzhi*, WANG Xiaoqin, CAO Meiqin
}

Key Laboratory of Spatial Data Mining and Information Sharing of Ministry of Education, National \& Local Joint Engineering Research Center of Satellite Geospatial Information Technology, Fuzhou University, Fuzhou 350108, China

\begin{abstract}
Land degradation has a major impact on environmental and socio-economic sustainability. Scientific methods are necessary to monitor the risk of land degradation. In this study, the environmental sensitive area index (ESAI) was utilized to assess land degradation sensitivity and convergence analysis in Korla, a typical oasis city in Xinjiang of China, which is located on the northeast border of the Tarim Basin. A total of 18 indicators depicting soil, climate, vegetation, and management qualities were used to illustrate spatial-temporal patterns of land degradation sensitivity from 1994 to 2018. We investigated the causes of spatial convergence and divergence based on the Ordinary Least Squares (OLS) and Geographically Weighted Regression (GWR) models. The results show that the branch of the Tianshan Mountains and oasis plain had a low sensitivity to land degradation, while the Tarim Basin had a high risk of land degradation. More than two-thirds of the study area can be categorized as "critical" sensitivity classes. The largest percentage $(32.6 \%)$ of fragile classes was observed for 2006. There was no significant change in insensitive or low-sensitivity areas, which accounted for less than $0.4 \%$ of the entire observation period. The ESAI of the four time periods (1994-1998, 1998-2006, 2006-2010, and 2010-2018) formed a series of convergence patterns. The convergence patterns of 1994-1998 and 1998-2006 can be explained by the government's efforts to "Returning Farmland to Forests" and other governance projects. In 2006-2010, the construction of afforested work intensified, but industrial development and human activities affected the convergence pattern. The pattern of convergence in most regions between 2010 and 2018 can be attributed to the government's implementation of a series of key ecological protection projects, which led to a decrease in sensitivity to land degradation. The results of this study altogether suggest that the ESAI convergence analysis is an effective early warning method for land degradation sensitivity.
\end{abstract}

Keywords: land degradation; quality index; convergence analysis; remote sensing; environmental sensitive area index; Korla

Citation: DING Jinchen, CHEN Yunzhi, WANG Xiaoqin, CAO Meiqin. 2020. Land degradation sensitivity assessment and convergence analysis in Korla of Xinjiang, China. Journal of Arid Land, 12(4): 594-608. https://doi.org/10.1007/s40333-020$0057-\mathrm{y}$

\section{Introduction}

Land degradation, which is affected by extreme climate events, rapid population growth, and unsustainable land management practices, poses a global environmental threat. It is a major challenge facing the survival and sustainable development of individuals and communities around the world (Abu and Tumeizi, 2012; Gibbs and Salmon, 2015; Dubovyk, 2017; Mao et al., 2018; Horion et al., 2019). Forms of severe land degradation have occurred in $10 \%-20 \%$ of the world's

\footnotetext{
*Corresponding author: CHEN Yunzhi (E-mail: chenyunzhi@fzu.edu.cn)

Received 2019-08-08; revised 2020-03-25; accepted 2020-04-27

(C) Xinjiang Institute of Ecology and Geography, Chinese Academy of Sciences, Science Press and Springer-Verlag GmbH Germany, part of Springer Nature 2020
} 
drylands, the consequences of which are estimated to directly affect about $250 \times 10^{6}$ people in the developing world (Reynolds et al., 2007). Xinjiang Uygur Autonomous Region has the widest distribution and largest area of desert lands in China (Zhang et al., 2014; Ran and Li, 2015). Korla, a typical oasis city in Xinjiang, has undergone a swift and strong economic development accompanied by both urban expansion and industrial production. This development has made the area's land supply and carrying capacity highly complex (Ma and Gao, 2017). The interactions among the Tarim River, Taklimakan Desert, and other systems further make the ecological environment of Korla fragile and increase the risk of land degradation (Li, 2018).

Land degradation is a complex and continuous dynamic process (Wang et al., 2014). Monitoring land degradation requires consideration of multiple factors. Based on remote sensing and GIS technologies, researchers used various indicators to identify the areas of land degradation. Key variables include spectral biophysical indicators, environmental indicators, and socio-economic indicators (Xu et al., 2009; Lamchin et al., 2016). Previous studies have generally lacked standardized methodology, however, or have centered on limited indicators (Weinzierl et al., 2016; Riva et al., 2017; Easdale et al., 2019). To comprehensively and straightforwardly describe the process of land degradation, it is possible to combine the quantitative and qualitative methods with specific indicators (Sommer et al., 2011; Salunkhe et al., 2018).

The environmental sensitive area index (ESAI) approach was developed in the context of identifying and assessing potentially degraded Mediterranean regions (Kosmas et al., 1999). It is implemented by considering significant factors resulting in land degradation, namely, soil, climate, vegetation, and management indicators. These indicators can facilitate a deeper understanding of land degradation sensitivity. Further, the ESAI approach has advantages of simple, flexible, and rapidly implementation, and it can be adjusted to different-level scales as per the conditions of the study area (Kosmas et al., 2003). As a widely recognized approach, the ESAI has been successfully applied to field sites in Europe, Mediterranean Basin, and Central Asia (Contador et al., 2009; Salvati and Zitti, 2009a; Basso et al., 2012; Prăvălie et al., 2017; Kolios et al., 2018; Jiang et al., 2019). However, there have been few previous studies on the land degradation sensitivity in oasis cities such as Korla.

The combination of land degradation sensitivity and convergence analysis is an extension of previous research. The concept of "convergence" originates in economists' measurements of the development gap among countries. It is widely used to in the study of economic and industrial development (Gugler and Pfaffermayr, 2004; Salvati and Zitti, 2009b; Manca et al., 2014), but rarely in the convergence analysis of environmental quality. In the context of environmental research, convergence analysis was firstly used to monitor the sensitivity of land degradation in Italy, which provided empirical evidence for spatial convergence at the country scale (Salvati and Zitti, 2008). In this study, convergence is indicative of a negative correlation between the differences in ESAI over a particular time interval and at the initial observation time. The ESAI with the lowest value is closer to the mean than other ESAI (Tombolini et al., 2016). Spatial convergence and divergence are applicable in assessments of regional land degradation and may provide a reference for governments in managing areas where degradation has occurred. Therefore, convergence analysis that includes environmental indicators may provide an evidence of the driving factors on land degradation. Results of convergence analysis can also serve as an early warning signal for land degradation sensitivity (Neumayer, 2001).

In this study, the ESAI of Korla from 1994 to 2018 was calculated using time-series, multi-source spatial data to determine the sensitivity of land degradation across the region in different years. The rationality of these results was verified by field investigation. The convergence of the time-series ESAI was used to identify "hotspots" in need of attention and to analyze the effects of the implementation of land management measures. The novelty of this work is its focus on typical oasis areas, its validation of the feasibility of the ESAI approach, and its establishment of suitable methods for evaluating land degradation sensitivity in the areas significantly impacted by human activities and natural factors. Most importantly, a spatial-temporal analysis of ESAI was conducted to identify areas that require a close attention. 
The goals of this study are to (1) monitor the quality index and spatial-temporal pattern of ESAI; (2) analyze the spatial convergence of ESAI at time intervals on a grid scale; and (3) determine the underlying mechanisms of the convergence and divergence patterns of ESAI. The results presented in this study may provide a scientific reference for optimizing land management and preventing land degradation in Korla, as well as other similar regions in the world.

\section{Materials and methods}

\subsection{Study area}

Korla City $\left(41^{\circ} 10^{\prime} 48^{\prime \prime}-42^{\circ} 21^{\prime} 36^{\prime \prime} \mathrm{N}, 85^{\circ} 14^{\prime} 10^{\prime \prime}-86^{\circ} 34^{\prime} 21^{\prime \prime} \mathrm{E}\right)$, located in the central part of Xinjiang Uygur Autonomous Region, China, is situated at the northeastern border of the Tarim Basin and crosses the southern reaches of the Tarim River alluvial fan (Fig. 1). It is situated in the Konqi River Delta, forming a vast and fan-shaped oasis plain. The northern part of Korla is a branch of the Tianshan Mountains that forms an alluvial fan in the front of the mountains. Korla has a total area of $7268 \mathrm{~km}^{2}$, with the length of $127 \mathrm{~km}$ and width of $105 \mathrm{~km}$ (Song et al., 2013). Korla has a temperate continental arid climate, with annual mean temperature of $11^{\circ} \mathrm{C}$, mean annual precipitation of $59 \mathrm{~mm}$, total annual solar irradiance time of $2990 \mathrm{~h}$, and mean annual evaporation of $2778 \mathrm{~mm}$. The favorable water, soil, light, and heat resources in Korla are very suitable for the growth of cash crops such as pear, cotton, and tomato (Liu et al., 2014).

At the end of 2018, the total population of Korla was $4.73 \times 10^{5}$ and the regional gross domestic product (GDP) was $6.16 \times 10^{10} \mathrm{CNY}$ (Statistic Bureau of Koral, 2018). Korla has gradually become an important modern city in Xinjiang. However, land degradation caused by desertification, salinization, over-exploitation of cultivated land, and droughts significantly influence the ecological environment of Korla. These problems threaten the coordinated development of economy, society, and environment in the city and its surrounding regions (Cai et al., 2015). There is an urgent need to effectively monitor land degradation sensitivity in this area.

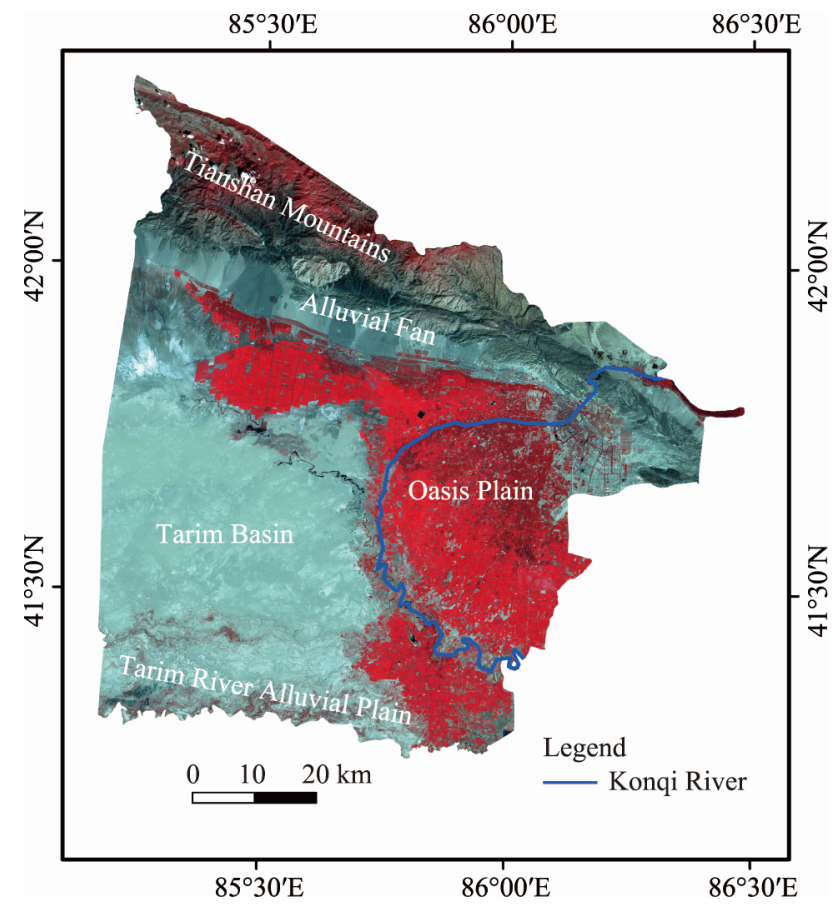

Fig. 1 Landsat TM imagery of the study area (Bands 5-4-3)

\subsection{Data and indicators}

The United Kingdom's Ministry of Agriculture, Fisheries, and Food launched the ESAI approach 
in 1987 to encourage farmers and landowners to adopt environmentally and friendly land management measures (Wilson, 1996). Through field surveys and both general and local knowledge of the environmental processes at work, Kosmas et al. (1999) improved the ESAI approach and applied it successfully in the Mediterranean Desertification and Land Use Project (MEDALUS).

According to the ESAI approach, we selected 18 indicators in this study to take into account four quality domains: soil, climate, vegetation, and management. Each quality indicator was calculated by the geometric mean of the relevant sub-indicators. The values of each sub-indicator were split into several classes and several scores were assigned accordingly. The thresholds of the scores were determined with reference to extensive field work by the MEDALUS and as per the actual situation of the study area (Kosmas et al., 1999). We assigned sensitivity scores between 1 (the lowest sensitivity) and 2 (the highest sensitivity) to each class based on the importance of its role in land degradation sensitivity and its relationship to the onset of the degradation process (Kosmas et al., 2014).

To ensure a strong spatial consistency across different indicators, we resampled the spatial resolution of all sub-indicator data to $300 \mathrm{~m}$ using the nearest neighborhood method and on the same projection system. A time period encompassing 24 years was assessed by observing the land degradation sensitivity at five specific time points: 1994, 1998, 2006, 2010, and 2018. A field survey on local land situations was carried out in August 2018. Some sites representing land conditions of sparse vegetation were selected to further analyze the sensitivity of land degradation.

\subsubsection{Soil quality index (SQI)}

Soil can maintain biological productivity and environmental quality while supporting the health of plants and animals in various ecosystems (Salvati et al., 2011). According to the ESAI approach, we considered six parameters (texture, slope, surface albedo, dryness, salinity, and moisture) in the assessment of soil quality (Table 1). Soil texture data were downloaded from the Chinese Resource and Environment Data Cloud Platform (http://www.resdc.cn). The resource was compiled based on a soil type map with a spatial scale of 1:1,000,000. Soil profile data were obtained from the Second Soil Census (Tang, 1989), where soil texture was divided by the contents of sand, silt, and clay. The "Advanced Spaceborne Thermal Emission and Reflection Radiometer" (ASTER) Global Digital Elevation Model Version 2 with a spatial resolution of $30 \mathrm{~m}$ was used to retrieve the slope. The exact dates on which Landsat images acquired were 24 August 1994, 4 September 1998, 10 September 2006, 20 August 2010, and 26 August 2018. These Landsat imagery scenes were chosen because they had almost no clouds and their acquisition dates were close together. All Landsat imagery scenes were radiometrically calibrated and atmospherically corrected. Surface albedo (Eq. 1), dryness (Eq. 2), salinity (Eq. 3), and moisture (Eq. 4) data were retrieved using Landsat images with a spatial resolution of $30 \mathrm{~m}$. The band calculation formulas are as follows:

Surface albedo $=0.356 \times \mathrm{B}+0.130 \times \mathrm{R}+0.373 \times \mathrm{NIR}+0.085 \times \mathrm{SWIR}_{1}+0.072 \times \mathrm{SWIR}_{2}-0.0018$,

$$
\text { Dryness }=\frac{\mathrm{SI}+\mathrm{IBI}}{2}=\frac{\frac{\left(\mathrm{SWIR}_{1}+\mathrm{R}\right)-(\mathrm{NIR}+\mathrm{B})}{\left(\mathrm{SWIR}_{1}+\mathrm{R}\right)+(\mathrm{NIR}+\mathrm{B})}+\frac{\frac{2 \times \mathrm{SWIR}_{1}}{\mathrm{SWIR}_{1}+\mathrm{NIR}}-\left(\frac{\mathrm{NIR}}{\mathrm{NIR}+\mathrm{R}}+\frac{\mathrm{G}}{\mathrm{G}+\mathrm{SWIR}_{1}}\right)}{\frac{\mathrm{SWIR} \mathrm{SWI}_{1}}{\mathrm{SWIR}_{1}+\mathrm{NIR}}+\left(\frac{\mathrm{NIR}}{\mathrm{NIR}+\mathrm{R}}+\frac{\mathrm{G}}{\mathrm{G}+\mathrm{SWIR}_{1}}\right)}}{\text { Salinity }=\sqrt{\mathrm{B} \times \mathrm{R}},},
$$

Moisture $=0.0315 \times \mathrm{B}+0.2021 \times \mathrm{G}+0.3102 \times \mathrm{R}+0.1594 \times \mathrm{NIR}-0.6806 \times \mathrm{SWIR}_{1}-0.6109 \times \mathrm{SWIR}_{2},(4)$

where $B$ is the blue band; $R$ is the red band; NIR is the near-infrared band; $\mathrm{SWIR}_{1}$ is the short-wave infrared band $1(1550-1750 \mathrm{~nm}) ; \mathrm{SWIR}_{2}$ is the short-wave infrared band $2(2090-2350 \mathrm{~nm})$; SI is the bare soil index; IBI is the index-based built-up index; and G is the green band.

The SQI was calculated as follows (Kosmas et al., 1999):

$\mathrm{SQI}=(\text { Texture } \times \text { Slope } \times \text { Surface albedo } \times \text { Soil dryness } \times \text { Soil salinity } \times \text { Soil moisture })^{1 / 6}$. 
Table 1 Calculation parameters of soil quality index (SQI)

\begin{tabular}{|c|c|c|c|c|}
\hline Indicator & Parameter & Class & Description & Score \\
\hline \multirow{23}{*}{ SQI } & \multirow{4}{*}{ Texture } & 1 & Loamy, sandy clay loam, and clay loam & 1.0 \\
\hline & & 2 & Sandy clay and silt loam & 1.2 \\
\hline & & 3 & Silt, clay, and silt clay & 1.6 \\
\hline & & 4 & Sand & 2.0 \\
\hline & \multirow{4}{*}{ Slope $(\%)$} & 1 & $<6$ & 1.0 \\
\hline & & 2 & $6-18$ & 1.2 \\
\hline & & 3 & $18-35$ & 1.5 \\
\hline & & 4 & $>35$ & 2.0 \\
\hline & \multirow{3}{*}{ Surface albedo } & 1 & Somber & 1.0 \\
\hline & & 2 & Moderately bright & 1.5 \\
\hline & & 3 & Bright & 2.0 \\
\hline & \multirow{4}{*}{ Soil dryness } & 1 & Low & 1.0 \\
\hline & & 2 & Moderate & 1.3 \\
\hline & & 3 & High & 1.6 \\
\hline & & 4 & Very high & 2.0 \\
\hline & \multirow{4}{*}{ Soil salinity } & 1 & None or slight & 1.0 \\
\hline & & 2 & Moderate & 1.4 \\
\hline & & 3 & Severe & 1.7 \\
\hline & & 4 & Very severe & 2.0 \\
\hline & \multirow{4}{*}{ Soil moisture } & 1 & Very high & 1.0 \\
\hline & & 2 & High & 1.3 \\
\hline & & 3 & Moderate & 1.7 \\
\hline & & 4 & Low & 2.0 \\
\hline
\end{tabular}

\subsubsection{Climate quality index (CQI)}

Severe climatic conditions such as low precipitation, gusty winds, and extreme temperatures can exacerbate land degradation. In this study, we assessed the CQI according to four parameters: precipitation, aridity index, aspect, and wind speed (Table 2). Precipitation and wind speed were taken from annual data sets of the National Meteorological Information Center (http://data.cma.cn/). The

Table 2 Calculation parameters of climate quality index (CQI)

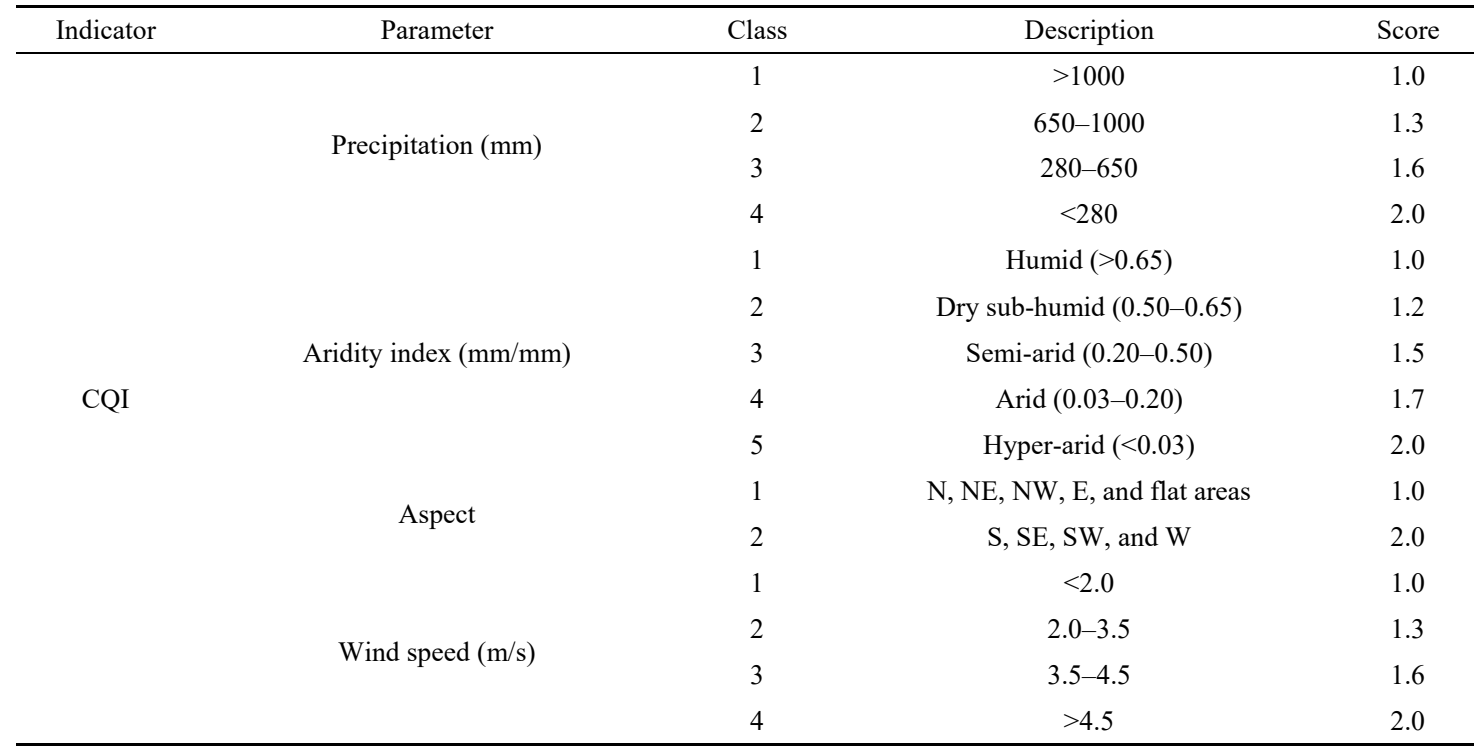


Australian National University Spline (ANUSPLINE) meteorological interpolation model (Liu et al., 2008) was used to interpolate the precipitation and wind speed data from meteorological stations of varying altitudes and locations during 1994-2018, and the spatial resolution was $300 \mathrm{~m}$. The aridity index (AI) with the spatial resolution of $1 \mathrm{~km}^{2}$ was collected from the Consortium for Spatial Information (CSI). The data are available at http://www.cgiar-csi.org. The AI was calculated using the equation: $\mathrm{AI}=\mathrm{P} / \mathrm{PET}$, where $\mathrm{P}$ is the annual precipitation $(\mathrm{mm})$ and $\mathrm{PET}$ is the annual potential evapotranspiration $(\mathrm{mm})$. Aspect is an important parameter that affects the angle and time at which sunlight strikes the soil surface, which can result in varying degrees of vegetation humidity (Kosmas et al., 1999). The ASTER Global Digital Elevation Model Version 2 (https://search.earthdata.nasa.gov) was used to calculate the aspect.

Specifically, the CQI was calculated as follows (Kosmas et al., 1999):

$$
\mathrm{CQI}=(\text { Precipitation } \times \text { Aridity inde } \times \text { Aspect } \times \text { Wind speed })^{1 / 4} \text {. }
$$

\subsubsection{Vegetation quality index (VQI)}

Vegetation regulates climate, maintains water and soil, reduces unwanted effects of wind and sand, and protects farmlands, especially in arid and semi-arid areas. The VQI was assessed in this study through four indicators: fire risk, erosion protection, drought resistance, and vegetation coverage (Table 3). The land use/cover map was provided by the European Space Agency the Climate Change Initiative-Land Cover (ESACCI-LC), a project that delivers consistent global land use/cover maps at $300 \mathrm{~m}$ spatial resolution on an annual basis. The data are available at http://maps.elie.ucl.ac.be/CCI/viewer/. The land use/cover map for the period of 1994-2018 was used to gather the detailed fire risk, erosion protection, and drought resistance information comprising the VQI. We then divided the results into different classes according to the land use/cover type.

Table 3 Calculation parameters of vegetation quality index (VQI)

\begin{tabular}{|c|c|c|c|c|}
\hline Indicator & Parameter & Class & Description & Score \\
\hline \multirow{19}{*}{ VQI } & \multirow{4}{*}{ Fire risk } & 1 & Agricultural crops, water, wetland, bare land, and urban areas & 1.0 \\
\hline & & 2 & Sparse vegetation & 1.3 \\
\hline & & 3 & Shrubland and grassland & 1.6 \\
\hline & & 4 & Evergreen forest and conifer forest & 2.0 \\
\hline & \multirow{5}{*}{ Erosion protection } & 1 & Evergreen forest, conifer forest, and urban areas & 1.0 \\
\hline & & 2 & Shrubland and grassland & 1.3 \\
\hline & & 3 & Sparse vegetation & 1.6 \\
\hline & & 4 & Agricultural crops & 1.8 \\
\hline & & 5 & Water, wetland, and bare land & 2.0 \\
\hline & \multirow{5}{*}{$\begin{array}{l}\text { Drought } \\
\text { resistance }\end{array}$} & 1 & Water, wetland, and urban areas & 1.0 \\
\hline & & 2 & Evergreen forest and conifer forest & 1.2 \\
\hline & & 3 & Shrubland and grassland & 1.4 \\
\hline & & 4 & Agricultural crops & 1.7 \\
\hline & & 5 & Sparse vegetation and bare land & 2.0 \\
\hline & \multirow{5}{*}{$\begin{array}{l}\text { Vegetation } \\
\text { coverage }(\%)\end{array}$} & 1 & $>75$ & 1.0 \\
\hline & & 2 & $50-75$ & 1.3 \\
\hline & & 3 & $25-50$ & 1.5 \\
\hline & & 4 & $10-25$ & 1.8 \\
\hline & & 5 & $<10$ & 2.0 \\
\hline
\end{tabular}

The dimidiate pixel model was used to calculate the vegetation coverage in each period (Eq. 7) via the normalized difference vegetation index (NDVI) (Eq. 8) to determine the vegetation status.

$$
F V C=\frac{N D V I-N^{2} I_{\text {soil }}}{N_{\text {DVI }}-\mathrm{NDVI}_{\text {soil }}} \times 100 \%,
$$




$$
\mathrm{NDVI}=\frac{\mathrm{NIR}-\mathrm{R}}{\mathrm{NIR}+\mathrm{R}}
$$

where FVC is the vegetation coverage (\%); $\mathrm{NDVI}_{\text {soil }}$ is the NDVI value of the pure soil cover pixel; $\mathrm{NDVI}_{\text {veg }}$ is the NDVI value of the pure vegetation cover pixel; NIR is the near-infrared band; and $\mathrm{R}$ is the red band.

The VQI was calculated as follows (Kosmas et al., 1999):

$$
\text { VQI }=(\text { Fire risk } \times \text { Erosion protection } \times \text { Drought resistance } \times \text { Vegetation coverage })^{1 / 4} \text {. }
$$

2.2.4 Management quality index (MQI)

Various anthropogenic environmental pressures and different forms of land use and management may affect land degradation sensitivity. In this study, the MQI was calculated using GDP, population density, agricultural intensity, and policy enforcement information (Table 4). GDP and population density data were obtained from the Chinese Resource and Environment Data Cloud Platform (http://www.resdc.cn). This data set uses the administrative area as a basic statistical unit to spread the population and GDP information onto a kilometer-level grid cell for spatialization. The original data can then be re-projected, re-sampled, and clipped as necessary. The agricultural intensity and policy enforcement information used here were originated from land use/cover maps provided by the ESACCI-LC with a spatial resolution of $300 \mathrm{~m}$. According to local agricultural systems, the agricultural intensity depended on the type of plant varieties, the mode of irrigation, the degree of mechanization, and the other related factors at work in the given area. We classified policy enforcement across three categories according to the degree of land protection (Table 4).

The MQI was calculated as follows (Kosmas et al., 1999):

$\mathrm{MQI}=(\text { GDP } \times \text { Population density } \times \text { Agricultural intensity } \times \text { Policy enforcement })^{1 / 4}$.

\begin{tabular}{|c|c|c|c|c|}
\hline Indicator & Parameter & Class & Description & Score \\
\hline \multirow{18}{*}{ MQI } & \multirow{6}{*}{$\begin{array}{l}\text { GDP (gross output } \\
\text { value } / \mathrm{km}^{2} \text { ) }\end{array}$} & 1 & $<500$ & 1.0 \\
\hline & & 2 & $500-1000$ & 1.2 \\
\hline & & 3 & $1000-1500$ & 1.4 \\
\hline & & 4 & $1500-2000$ & 1.6 \\
\hline & & 5 & $2000-4000$ & 1.8 \\
\hline & & 6 & $>4000$ & 2.0 \\
\hline & \multirow{6}{*}{$\begin{array}{l}\text { Population density } \\
\left(\text { people } / \mathrm{km}^{2}\right)\end{array}$} & 1 & $<20$ & 1.0 \\
\hline & & 2 & $20-60$ & 1.2 \\
\hline & & 3 & $60-100$ & 1.4 \\
\hline & & 4 & $100-150$ & 1.6 \\
\hline & & 5 & $150-200$ & 1.8 \\
\hline & & 6 & $>200$ & 2.0 \\
\hline & \multirow{3}{*}{ Agricultural intensity } & 1 & $\begin{array}{c}\text { Evergreen forest, conifer forest, urban areas, water, wetland, bare } \\
\text { land, and sparse vegetation }\end{array}$ & 1.0 \\
\hline & & 2 & Grassland and shrubland & 1.5 \\
\hline & & 3 & Agricultural crops & 2.0 \\
\hline & \multirow{3}{*}{ Policy enforcement } & 1 & Urban areas & 1.0 \\
\hline & & 2 & Agricultural crops, water, wetland, grassland, and shrubland & 1.5 \\
\hline & & 3 & Evergreen forest, conifer forest, sparse vegetation, and bare land & 2.0 \\
\hline
\end{tabular}

Table 4 Calculation parameters of management quality index (MQI)

2.2.5 Environmental sensitive area index (ESAI)

The ESAI is given by the geometric mean of four quality indices described above. The formula is described as follows (Kosmas et al., 1999):

$$
\mathrm{ESAI}=(\mathrm{SQI} \times \mathrm{CQI} \times \mathrm{VQI} \times \mathrm{MQI})^{1 / 4} \text {. }
$$

According to the scoring system proposed by the MEDALUS, ESAI values range from 1 (the 
lowest sensitivity) to 2 (the highest sensitivity). ESAI values can cover as diverse a range of land sensitivity to degradation as possible. Table 5 shows that ESAI values may be divided into eight classes reflecting the most commonly used classification thresholds (Kosmas et al., 1999; Basso et al., 2000; Salvati et al., 2011; Prăvălie et al., 2017).

Table 5 Classes and corresponding ranges of environmental sensitive area index (ESAI)

\begin{tabular}{ccc}
\hline Score range & Class & Description \\
\hline$<1.17$ & $\mathrm{~N}$ (non-affected) & $\begin{array}{c}\text { Insensitive to land degradation } \\
\text { Low sensitivity to land degradation }\end{array}$ \\
$1.17-1.22$ & $\mathrm{P}$ (potential) & Moderately sensitive to land degradation \\
$1.23-1.26$ & $\mathrm{~F}$ 1 (fragile 1) & Moderately sensitive to land degradation \\
$1.27-1.32$ & $\mathrm{~F} 2$ (fragile 2) & Moderately sensitive to land degradation \\
$1.33-1.37$ & $\mathrm{~F} 3$ (fragile 3) & Highly or very highly sensitive to land degradation \\
$1.38-1.41$ & $\mathrm{C}$ ( critical 1) & Highly or very highly sensitive to land degradation \\
$1.42-1.53$ & $\mathrm{C} 2$ (critical 2) & Highly or very highly sensitive to land degradation \\
\hline
\end{tabular}

\subsection{Methodology}

\subsubsection{Spatial-temporal variation trend surface analysis}

Trend surface analysis not only reveals the spatial variation trends of data in different directions but also provides the optimal trend surface through function fitting. The trend surface reflects the overall variation of spatial objects in the spatial region ( $\mathrm{Li}$ et al., 2012). In this study, trend surface analysis was used to project ESAI values onto planes in the east-west direction and the north-south direction of the study area. Function fitting was performed to obtain an optimal function curve that represents the trend of these projection points corresponding to the overall spatial-temporal variation trend of ESAI values. The final quadratic trend surface model has sufficient fitting accuracy. Its binary regression function is described as follows (Wang and Zuo, 2015):

$$
Z=a_{0}+a_{1} x+a_{2} y+a_{3} x^{2}+a_{4} x y+a_{5} y^{2}+\varepsilon,
$$

where the spatial coordinates $(x, y)$ of the sample points are independent variables; $Z$ is the dependent variable; $a_{0}, a_{1}, a_{2}, a_{3}, a_{4}$, and $a_{5}$ are the polynomial coefficients; and $\varepsilon$ is the error term.

\subsubsection{Convergence analysis}

"Convergence", in this context, refers to a negative correlation between the change rate of ESAI values and the ESAI value of the initial year during a particular time interval. Different regions have different initial ESAI values, and low-value regions may have faster growth rates. As time progresses, all regions will converge to the mean ESAI value, i.e., "reaching convergence". The average value of ESAI and annual average rate of different intervals were calculated as discussed in detail below.

The following ordinary least squares (OLS) model (Kramer and Donninger, 1987; Tu and Xia, 2008; Afendras and Markatou, 2016) was used to measure the overall spatial convergence of ESAI in Korla:

$$
y_{i}=\beta_{0}+\sum_{j=1}^{k} \beta_{j} x_{i j}+\varepsilon_{i},
$$

where $y_{i}$ represents the change rate of ESAI at the corresponding time interval; $\beta_{0}$ is a constant term; $\beta_{j}$ is a regression coefficient; $i$ is the number of observations; $x_{i j}(j=1,2, \ldots, k)$ represents the ESAI value of the $i^{\text {th }}$ spatial domain in the $j^{\text {th }}$ year; and $\varepsilon_{i}$ is a random error term that conforms to a normal distribution. The coefficient $\beta_{j}$ is statistically significant $(P<0.01)$ based on $F$-tests. A positive coefficient indicates a divergent ESAI trend, while a negative coefficient indicates a convergent ESAI trend (Salvati and Zitti, 2009b).

The geographically weighted regression (GWR) model (Brunsdon et al., 1996) was used to identify the local spatial convergence of ESAI in Korla. A fixed weight Gaussian function was selected here as a spatial weight function and the AIC (Akaike Information Criterion) method was 
used to determine the bandwidth of the weight function (Wang et al., 2005). The ESAI regression coefficient was obtained by local regression using data from adjacent observation points, and it varied with geographic location. The convergence analysis was estimated as follows (McMillen, 2004; Tu and Xia, 2008; Ogneva et al., 2009; Liu et al., 2019):

$$
y_{i}=\beta_{0}\left(u_{i}, v_{i}\right)+\sum_{j=1}^{k} \beta_{j}\left(u_{i}, v_{i}\right) x_{i j}+\varepsilon_{i},
$$

where $y_{i}$ represents the change rate of ESAI at the corresponding time interval; $\beta_{0}$ is a constant term; $\left(u_{i}, v_{i}\right)$ is the geographic center coordinate of the $i^{\text {th }}$ spatial domain; $\beta_{0}\left(u_{i}, v_{i}\right)$ is a constant term; $\beta_{j}\left(u_{i}, v_{i}\right)$ is the $j^{\text {th }}$ regression coefficient of the $i^{\text {th }}$ spatial domain; $x_{i j}(j=1,2, \ldots, k)$ represents the ESAI value of the $i^{\text {th }}$ spatial domain in the $j^{\text {th }}$ year; and $\varepsilon_{i}$ is an error that obeys an independent normal distribution with a mean of zero. A positive ESAI regression coefficient indicates a divergent ESAI trend in the corresponding region, while a negative ESAI regression coefficient indicates a convergent ESAI trend in the corresponding region (Tombolini et al., 2016).

\section{Results}

\subsection{Spatial assessment of ESAI from 1994 to 2018}

Figure 2 shows the spatial distribution of ESAI in Korla. Regions susceptible to land degradation were scattered throughout the study area. Generally, low ESAI values were concentrated in the branch of the Tianshan Mountains and the oasis plains, while high ESAI values were concentrated in the Tarim Basin, alluvial fan, and Tarim River alluvial plain, which represented the regions most susceptible to land degradation in Korla. The sensitivity of land degradation in desert areas was higher than that in mountains and oasis plains as expected. Anthropogenic activity had a little impact on grasslands in the branch of the Tianshan Mountains, so any slight changes may be a response to climatic factors.

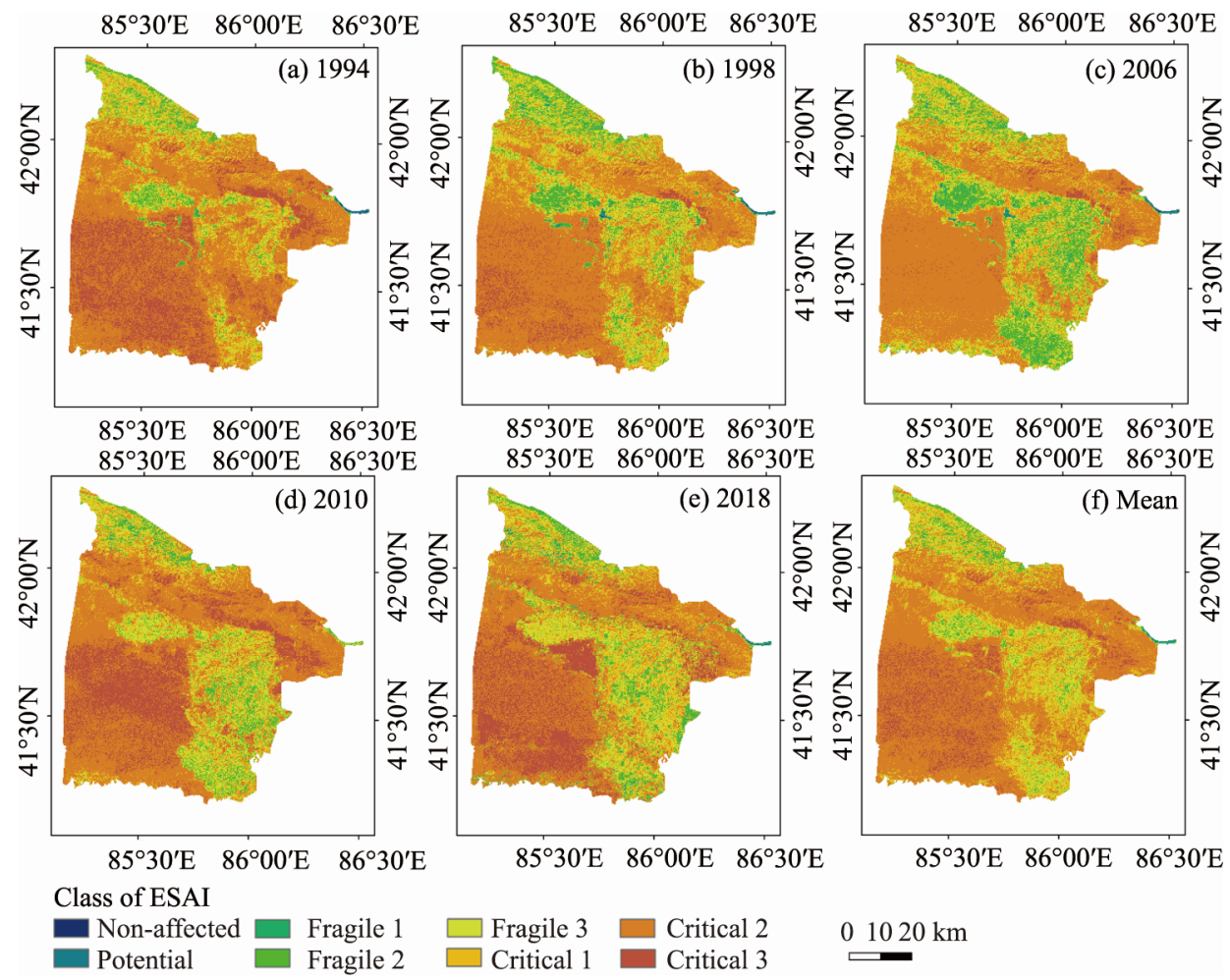

Fig. 2 Spatial distributions of ESAI (environmental sensitive area index) in 1994 (a), 1998 (b), 2006 (c), 2010 (d), and 2018 (e), and spatial distribution of mean ESAI from 1994 to 2018 (f), as represented by different sensitivity classes of ESAI. The description of sensitivity classes is shown in Table 5. 
Table 6 shows the area percentage of each ESAI sensitivity class. Across the observation period, most of the study area fell into critical classes. The area percentage of critical classes accounted for $85.42 \%$ of the total area in 1994 , but in 2006 it fell sharply to $66.98 \%$ before increasing to $76.33 \%$ in 2018. The fragile classes were mainly concentrated in the branch of the Tianshan Mountains and the oasis plains. In $1994,14.39 \%$ of the total area belonged to these classes. This percentage remained above $20.00 \%$ from 1998 to 2018 . Area percentage of non-affected and potential classes showed no significantly changes and accounted for less than $0.40 \%$ of the total area. In general, the sensitivity of land degradation in Korla declined over the study period.

Table 6 Area percentages of ESAI sensitivity classes in different years

\begin{tabular}{cccccc}
\hline Class & \multicolumn{5}{c}{ Area percentage (\%) } \\
\cline { 2 - 6 } & 1994 & 1998 & 2006 & 2010 & 2018 \\
\hline Non-affected & 0.04 & 0.04 & 0.03 & 0.00 & 0.02 \\
Potential & 0.15 & 0.33 & 0.39 & 0.03 & 0.31 \\
Fragile 1 & 0.41 & 1.50 & 2.35 & 0.40 & 1.22 \\
Fragile 2 & 4.91 & 9.02 & 13.89 & 6.97 & 7.38 \\
Fragile 3 & 9.07 & 14.98 & 16.36 & 13.83 & 14.74 \\
Critical 1 & 12.77 & 15.42 & 15.14 & 12.00 & 13.25 \\
Critical 2 & 53.75 & 52.64 & 49.96 & 47.75 & 45.49 \\
Critical 3 & 18.90 & 6.07 & 1.88 & 19.02 & 17.59 \\
\hline
\end{tabular}

Overall, the sensitivity of land degradation in the west of Korla was much higher than that in the east (Fig. 3). These four land conditions of sparse vegetation of Tamarix ramosissima (Fig. 3a), cotton intensive agricultural areas (Fig. 3b), severely saline-alkali soils (Fig. 3c), and extensive desert areas (Fig. 3d) corresponded to the fragile 3, fragile 1, critical 2, and critical 3 classes, respectively. It can be seen that the ESAI accurately reflects this condition: high ESAI values are related to harsh environmental conditions. The land degradation differences among different locations in the field survey were consistent with the corresponding ESAI classification results.

The trend line of land degradation sensitivity according to spatial statistical analysis in ArcGIS is shown in Figure 4. The blue line indicates the land degradation sensitivity trend in the east-west direction and the green line represents the trend in the north-south direction. The trend lines in the north-south direction formed convex curves in certain periods, indicating that the spatial distribution of ESAI was high in the middle and low on both sides of the study area. The spatial distribution of ESAI was the opposite in the east-west direction, i.e., low in the middle and high on both sides. The trend line of land degradation sensitivity was steeper in 2006 and 2010 (Figs. 4c and d), which indicates that land degradation sensitivity not only presents spatial differences of Korla but also changes in state and speed in different years.

\subsection{Convergence analysis of ESAI}

The convergence patterns were used to study the relationship between ESAI at the beginning of the time intervals assessed $(1994,1998,2006$, and 2010) and the difference over four respective time intervals (1994-1998, 1998-2006, 2006-2010, and 2010-2018). The coefficients of the four time periods obtained by the OLS model were $-0.0095,-0.0102,-0.0114$, and -0.0081 , respectively, which indicates that there is a convergence trend in each period and the land conditions in Korla are stabilizing over time.

The coefficients and local $R^{2}$ values of the ESAI spatial convergence analysis based on the GWR model at four time intervals are shown in Figure 5. Land degradation sensitivity in $96.93 \%$ of the study area showed convergence, and the convergence effect of the oasis plains was higher than that of the other regions from 1994 to 1998 (Figs. 5a1 and a2). During the period 1998-2006, regions with highly convergence were concentrated in the southeast with high local $R^{2}$ values, which suggests that ESAI tends to converge in the southeast during those years (Figs. $5 \mathrm{~b} 1$ and b2). From 2006 to 2010, the positive ESAI coefficients showing divergence were concentrated in the branch of the Tianshan Mountains and the oasis-desert ecotone with low local $R^{2}$ values, while regions with a higher convergence increased compared to the previous year and were mainly distributed in 
the oasis plains with high local $R^{2}$ values (Figs. $5 \mathrm{c} 1$ and $\mathrm{c} 2$ ). Up to $18.95 \%$ of the regions were divergent in the oasis-desert ecotone, alluvial fan, and Tarim River alluvial plain; and the convergent regions were concentrated in the oasis plains with high local $R^{2}$ values for the period 2010-2018 (Figs. 5d1 and d2). In general, land degradation sensitivity tended to converge between 1994 and 2018. The ESAI converged or diverged faster in regions with high land quality than in regions with low land quality.

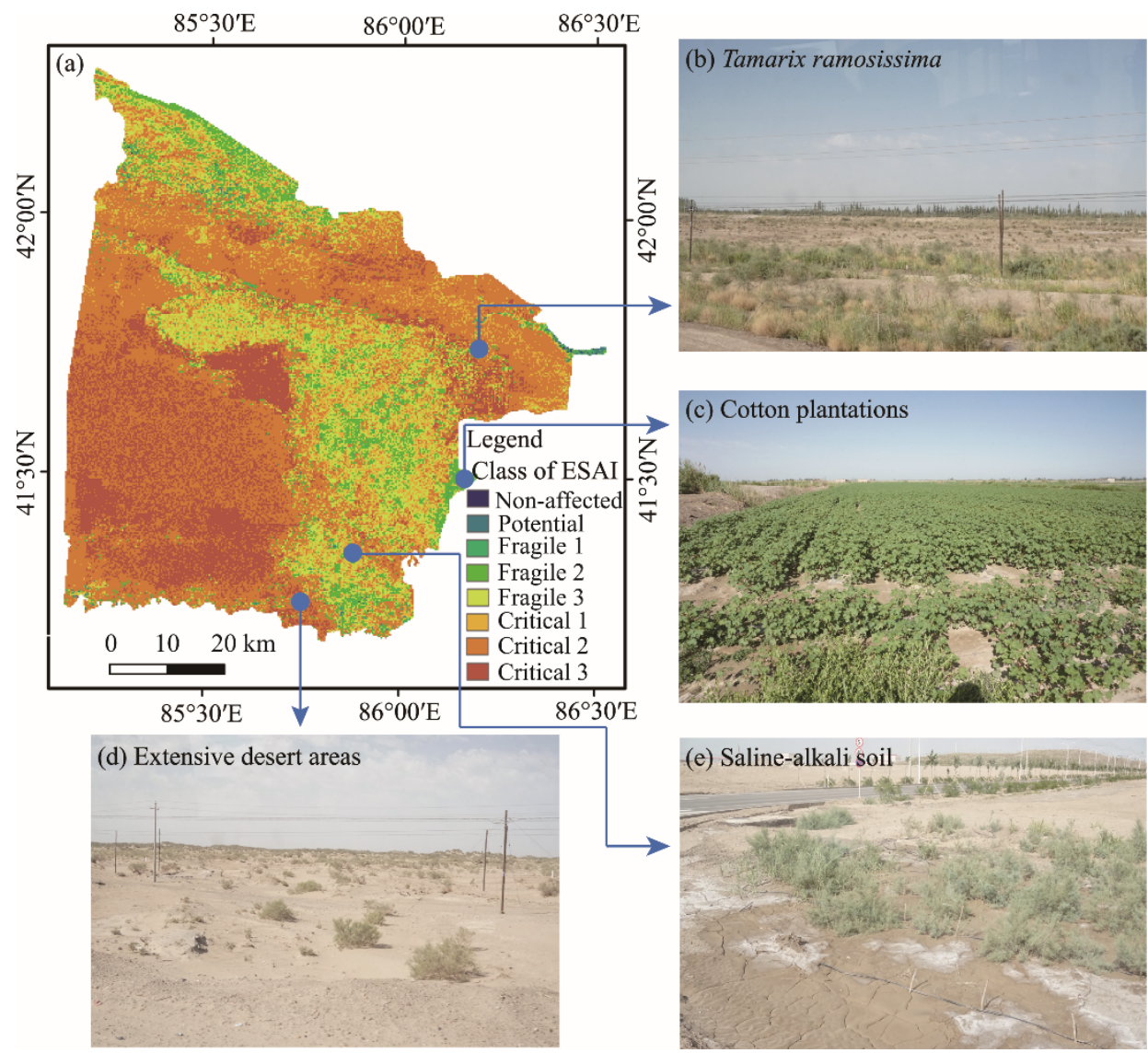

Fig. 3 Spatial distribution of ESAI in 2018 (represented by different sensitivity classes; a) and the field survey photos of land degradation sensitivity areas (b, Tamarix ramosissima; c, cotton plantations; d, extensive desert areas; and e, saline-alkali soil)
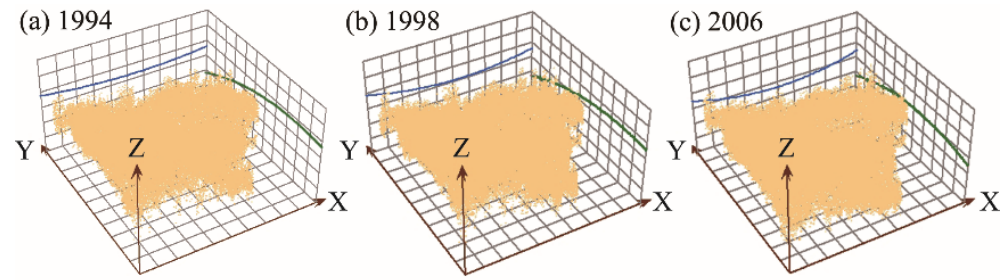

(d) 2010

(e) 2018

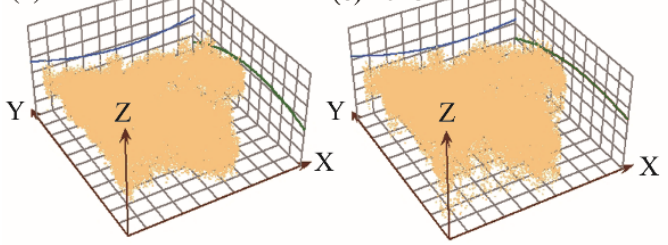

Legend

- East-west trend line

- North-south trend line

Fig. 4 Spatial trend surface analysis of land degradation sensitivity in 1994 (a), 1998 (b), 2006 (c), 2010 (d), and $2018(\mathrm{e})$ 




Fig. 5 Spatial distributions of coefficients and local $R^{2}$ values of the ESAI spatial convergence analysis from the geographically weighted regression (GWR) model over the time intervals of 1994-1998 (a1 and a2), 1998-2006 (b1 and b2), 2006-2010 (c1 and c2), and 2010-2018 (d1 and d2)

\section{Discussion}

In this study, we assessed a total of 18 indicators depicting soil, climate, vegetation, and management qualities according to the ESAI approach. The land degradation sensitivity and spatial convergence analysis of ESAI information were used to determine the potential land degradation in Korla from 1994 to 2018. The spatial convergence analysis reflects a series of complex interactions between ecological conditions and socio-economic backgrounds at different time intervals. Convergence patterns were observed in most regions over sequential time intervals. The convergence process gradually consolidates gaps between vulnerable regions. The oasis plains of Korla, which exhibited high land quality, were subject to relatively high anthropogenic environmental pressures (e.g., population growth, urban expansion, and crop intensification). The Taklimakan Desert in the western part of Korla showed a low-quality natural capital due to its harsh ecological environment and high sensitivity to land degradation (Yan et al., 2015).

The convergence pattern of ESAI during the period 1994-1998 reflected the impact of macrocontrol measures such as city planning and industrial development. To strengthen the ecological environment, the local government of Korla implemented the "Returning Farmland to Forest" Program to encourage more farmers to plant fruit trees such as pears and red dates, and to stoke the enthusiasm of farmers by increasing subsidies for releasing their farmlands to forests (Song et al., 2013). In addition, Korla has successively launched the "Three-North" Shelterbelt Project, resulting in remarkable achievements in forestry development (Abasi and Kasimu, 2015).

During the period 1998-2006, the Chinese government implemented the "Western Development Strategy", which significantly accelerated the development of Korla. The population shifted from rural areas toward cities as urbanization grew rapidly, leading to a gradual increase in land bearing capacity (Emin and Simayi, 2014). The promotion of advanced agricultural irrigation technology has also strengthened the agriculture sector of Korla considerably. The ecosystem has been indirectly protected by these measures and the land use structure has been continuously adjusted. Thus, the areas of various major land use types have changed significantly (Figs. $2 b$ and c). Areas 
of cultivated land, garden, forest, and under-construction land showed overall upward trends while area of unused land decreased (Miao et al., 2012). The convergence pattern of ESAI during the observation period appears to be influenced by the plans of urban development and governance project.

During the period 2006-2010, the construction of afforestation intensified, especially the construction of the Kongqi River Tourism Scenic Belt Project, which greatly improved the public green space of the city. As shown in Figure 5c1, a convergence phenomenon emerged nearby the Kongqi River Basin. The rapidly developing industry has brought a certain load to the environment. Building sites increasingly occupied large areas of land and have reduced the available green space. The divergence pattern of the partial regions is shown in Figure 5c1, which reflects the impact of anthropogenic activity (Aizezi et al., 2014).

From 2010 to 2018, both land urbanization and population growth resulted in an increase in the development of Korla (Ma and Gao, 2017). The divergence pattern appeared to be significantly affected by the scale of anthropogenic activities. The government adopted effective farmland protection measures and scientific urban planning layouts, increased land development and rectification efforts, and realized a balance of cultivated land occupation and compensation (Maimaiti et al., 2017). The city structure was continuously optimized and adjusted alongside breakthroughs in industrialization. Advanced urbanization has increased public awareness of cultivated land protection. In 2018, the government continued to implement key ecological projects such as the northern ecological protection corridor, natural forest protection, sand control, and soil and water conservation efforts to improve the protection of natural Populus euphratica forests (regarded as an ecological security barrier system) on the lower reaches of the Kongqi River, which has reduced the land degradation sensitivity of Korla.

\section{Conclusions}

In this study, the ESAI approach was used to assess the land degradation sensitivity in Korla from 1994 to 2018. A convergence analysis on the ESAI was performed at different time intervals. The land degradation sensitivity of Korla not only presents spatial differences but also changes in state and speed in different years. In general, land degradation sensitivity in Korla declined over the years examined in this study. The ESAI values in four time periods showed a convergence pattern, suggesting that land conditions are growing increasingly stable in Korla. The ESAI converged or diverged faster in areas with high land quality than those with low land quality.

Limited data availability and spatial resolution restricted the analyses presented in this paper in regards to the sensitivity of land degradation at five time nodes. In the future, under permission for further data acquisition, it will be possible to analyze longer-term series with finer temporal resolution. The precise mechanism of land degradation also merits further research to elucidate the impact of various indicators on land degradation sensitivity. It is yet necessary to secure a workable reference for further research on the dynamic changes and convergence of land degradation sensitivity in arid areas.

\section{Acknowledgements}

This work was supported by the National Key Research and Development Program of China (2017YFB0504203), the Central Government Guides Local Development Special Fund (2017L3012), and the National Natural Science Foundation of China (41771468, 41471362). The authors also gratefully acknowledge the US Geological Survey for providing free Landsat images, and other relative agencies for their freely available datasets.

\section{References}

Abasi G, Kasimu A. 2015. Analysis on correlation between cultivated land resources and urbanization development in Korla City. Research of Soil and Water Conservation, 22(4): 305-309. (in Chinese)

Abu H A, Tumeizi A. 2012. Land degradation: Socioeconomic and environmental causes and consequences in the eastern Mediterranean. Land Degradation and Development, 23(3): 216-226. 
Afendras G, Markatou M. 2016. Uniform integrability of the OLS estimators, and the convergence of their moments. TEST, 25(4): 775-784.

Aizezi A, Wang Y, Huang S W. 2014. Ecological security evaluation of resource-based cities in South Xinjiang: A case study of Korla City. Journal of Anhui Agricultural Sciences, 42(30): 10693-10697. (in Chinese)

Basso B, De S L, Cammarano D, et al. 2012. Evaluating responses to land degradation mitigation measures in southern Italy. International Journal of Environmental Research, 6(2): 367-380.

Basso F, Bove E, Dumontet S, et al. 2000. Evaluating environmental sensitivity at the basin scale through the use of geographic information systems and remotely sensed data: An example covering the Agri basin (southern Italy). Catena, 40(1): 19-35.

Brunsdon C, Fotheringham A S, Charlton M E. 1996. Geographically weighted regression: A method for exploring spatial nonstationarity. Geographical Analysis, 28(4): 281-298.

Cai Z Z, An S Z, Pu Z, et al. 2015. A study on vegetation coverage change in Korla City based on the TM NDVI. Pratacultural Science, 32(7): 1069-1078. (in Chinese)

Contador J F L, Schnabel S, Gutierrez A G, et al. 2009. Mapping sensitivity to land degradation in extremadura. SW Spain. Land Degradation and Development, 20(2): 129-144.

Dubovyk O. 2017. The role of Remote Sensing in land degradation assessments: Opportunities and challenges. European Journal of Remote Sensing, 50(1): 601-613.

Easdale M H, Farina C, Hara S, et al. 2019. Trend-cycles of vegetation dynamics as a tool for land degradation assessment and monitoring. Ecological Indicators, 107: 105545, doi: 10.1016/j.ecolind.2019.105545.

Emin M, Simayi Z. 2014. Coupling analysis of urbanization process to ecological environment of Korla City. Arid Land Geography, 37(1): 188-194. (in Chinese)

Gibbs H K, Salmon J M. 2015. Mapping the world's degraded lands. Applied Geography, 57: 12-21.

Gugler K, Pfaffermayr M. 2004. Convergence in structure and productivity in European Manufacturing? German Economic Review, 5(1): 61-79.

Horion S, Ivits E, De K W, et al. 2019. Mapping European ecosystem change types in response to land-use change, extreme climate events, and land degradation. Land Degradation and Development, 30(8): 951-963.

Jiang L L, Bao A M, Jiapaer G, et al. 2019. Monitoring land sensitivity to desertification in Central Asia: Convergence or divergence? Science of the Total Environment, 658: 669-683.

Kolios S, Mitrakos S, Stylios C. 2018. Detection of areas susceptible to land degradation in Cyprus using remote sensed data and environmental quality indices. Land Degradation and Development, 29(8): 2338-2350.

Kosmas C, Ferrara A, Briassouli H, et al. 1999. Methodology for Mapping Environmentally Sensitive Areas (ESAs) to desertification. Strasbourg: European Commission-Office for Official Publications of the European Communities, 1-87.

Kosmas C, Tsara M, Moustakas N, et al. 2003. Identification of indicators for desertification. Annals of Arid Zone, 42(3): 393416.

Kosmas C, Kairis O, Karavitis C, et al. 2014. Evaluation and selection of indicators for land degradation and desertification monitoring: Methodological approach. Environmental Management, 54(5): 951-970.

Kramer W, Donninger C. 1987. Spatial autocorrelation among errors and the relative efficiency of OLS in the linear regression model. Journal of the American Statistical Association, 82(398): 577-579.

Lamchin M, Lee J Y, Lee W K, et al. 2016. Assessment of land cover change and desertification using remote sensing technology in a local region of Mongolia. Advances in Space Research, 57(1): 64-77.

Li C E. 2018. Spatial-temporal variation of land desertification in Xinjiang. Science of Surveying and Mapping, 43(9): 33-39. (in Chinese)

Li M Y, Liu F, Xu T, et al. 2012. Mining of spatial data of forest resources based on GIS: A case study of Zijin Mountain. Journal of Northwest Forestry University, 27(3): 180-186. (in Chinese)

Liu C X, Wu X L, Wang L. 2019. Analysis on land ecological security change and affect factors using RS and GWR in the Danjiangkou Reservoir area, China. Applied Geography, 105: 1-14.

Liu J K, Zhong S Q, Chen Y L, et al. 2014. Study on extracting method of Korla Pear information based on satellite Remote Sensing data. Science Technology and Engineering, 14(26): 190-196. (in Chinese)

Liu Z H, Mcvicar T R, Li L T, et al. 2008. Introduction of the professional interpolation software for meteorology data: ANUSPLINN. Meteorological Monthly, 34(2): 92-100. (in Chinese)

Ma X K, Gao M H. 2017. Dynamic assessment of land ecologic safety of oasis city in arid northwest China: A case of Korla City in Xinjiang. Arid Land Geography, 40(1): 172-180. (in Chinese)

Maimaiti B, Ding J L, Simayi Z, et al. 2017. Characteristics of urban spatial expansion and its driving factors in Korla City. Journal of Glaciology and Geocryology, 39(2): 443-452. (in Chinese)

Manca G, Attaway D F, Waters N. 2014. Program assessment and the EU's agrienvironmental Measure 214: An investigation of the spatial dynamics of agrienvironmental policies in Sardinia, Italy. Applied Geography, 50: 24-30.

Mao D H, Wang Z M, Wu B F, et al. 2018. Land degradation and restoration in the arid and semiarid zones of China: Quantified 
evidence and implications from satellites. Land Degradation and Development, 29(11): 3841-3851.

McMillen D P. 2004. Geographically weighted regression: The analysis of spatially varying relationships. American Journal of Agricultural Economics, 86(2): 554-556.

Miao L J, Liu Q, He B, et al. 2012. The impact of Korla's urbanization process on regional land use change. Journal of Arid Land Resources and Environment, 26(10): 162-168. (in Chinese)

Neumayer E. 2001. Improvement without convergence: Pressure on the environment in European Union countries. Journal of Common Market Studies, 39(5): 927-937.

Ogneva H Y, Pearsall H, Rakshit R. 2009. Concrete evidence \& geographically weighted regression: A regional analysis of wealth and the land cover in Massachusetts. Applied Geography, 29(4): 478-487.

Prăvălie R, Săvulescu I, Patriche C, et al. 2017. Spatial assessment of land degradation sensitive areas in southwestern Romania using modified MEDALUS method. Catena, 153: 114-130.

Ran Q Y, Li N. 2015. Ecological security assessment based on PSR model: A case study of Xinjiang Uygur Autonomous Region. Ecological Economy, 31(7): 114-117. (in Chinese)

Reynolds J F, Stafford S D M, Lambin E F, et al. 2007. Global desertification: Building a science for dryland development. Science, 316(5826): 847-851.

Riva M J, Daliakopoulos I N, Eckert S, et al. 2017. Assessment of land degradation in Mediterranean forests and grazing lands using a landscape unit approach and the normalized difference vegetation index. Applied Geography, 86: 8-21.

Salunkhe S S, Bera A K, Rao S S, et al. 2018. Evaluation of indicators for desertification risk assessment in part of Thar Desert Region of Rajasthan using geospatial techniques. Journal of Earth System Science, 127(8): 1-24.

Salvati L, Zitti M. 2008. Regional convergence of environmental variables: Empirical evidences from land degradation. Ecological Economics, 68(1-2): 162-168.

Salvati L, Zitti M. 2009a. Assessing the impact of ecological and economic factors on land degradation vulnerability through multiway analysis. Ecological Indicators, 9(2): 357-363.

Salvati L, Zitti M. 2009b. Convergence or divergence in desertification risk? Scale-based assessment and policy implications in a Mediterranean country. Journal of Environmental Planning and Management, 52(7): 957-971.

Salvati L, Bajocco S, Ceccarelli T, et al. 2011. Towards a process-based evaluation of land vulnerability to soil degradation in Italy. Ecological Indicators, 11(5): 1216-1227.

Sommer S, Zucca C, Grainger A, et al. 2011. Application of indicator systems for monitoring and assessment of desertification from national to global scales. Land Degradation and Development, 22(2): 184-197.

Song G, Wang J S, He L H, et al. 2013. Simulation of land use change in western arid region under different scenarios based on the CLUE-S model. Journal of Nanjing Forestry University (Natural Science Edition), 37(3): 135-139. (in Chinese)

Statistic Bureau of Koral. Statistical Communique of National Economic and Social Development of Koral in 2018. Koral: Statistic Bureau of Koral. [2019-09-13]. http://www.xjkel.gov.cn/gk/shfwl/tjgb/202171.htm.

Tang J C. 1989. The second nationwide general soil survey and the developments in soil and fertilizer sciences. Acta Pedologica Sinica, 26(3): 234-240. (in Chinese)

Tombolini I, Colantoni A, Renzi G, et al. 2016. Lost in convergence, found in vulnerability: A spatially-dynamic model for desertification risk assessment in Mediterranean agro-forest districts. Science of the Total Environment, 569-570: 973-981.

Tu J, Xia Z G. 2008. Examining spatially varying relationships between land use and water quality using geographically weighted regression I: Model design and evaluation. Science of the Total Environment, 407(1): 358-378.

Wang H C, Zuo R G. 2015. A comparative study of trend surface analysis and spectrum-area multifractal model to identify geochemical anomalies. Journal of Geochemical Exploration, 155: 84-90.

Wang Q, Ni J, Tenhunen J. 2005. Application of a geographically-weighted regression analysis to estimate net primary production of Chinese forest ecosystems. Global Ecology and Biogeography, 14(4): 379-393.

Wang W L, Dong Z B, Yan C Z. 2014. Trend analysis on land degradation in Zoige Plateau based on landscape structure methods. Journal of Arid Land Resources and Environment, 28(10): 117-122. (in Chinese)

Weinzierl T, Wehberg J, Boehner J, et al. 2016. Spatial assessment of land degradation risk for the Okavango River Catchment, Southern Africa. Land Degradation and Development, 27(2): 281-294.

Wilson G A. 1996. Farmer environmental attitudes and ESA participation. Geoforum, 27(2): 115-131.

Xu D Y, Kang X W, Qiu D S, et al. 2009. Quantitative assessment of desertification using Landsat data on a regional scale: A case study in the Ordos Plateau, China. Sensors, 9(3): 1738-1753.

Yan H, Wang Y J, Zhang H L. 2015. Ecological sensitivity of Bayingolin Mongolian Autonomous Prefecture of Xinjiang. Arid Land Geography, 38(6): 1226-1233. (in Chinese)

Zhang Z W, Yang F X, Wu J L, et al. 2014. Spatial distribution patterns and type structure of the deserts in Xinjiang. Arid Zone Research, 31(4): 763-770. (in Chinese) 